\title{
Electrochemical Benzylic C-H Functionalization with Isocyanides
}

\author{
Shanyu Tang, ${ }^{a}$ Régis Guillot, ${ }^{\mathrm{a}}$ Laurence Grimaud, ${ }^{* \mathrm{~b}}$ Maxime Vitale, ${ }^{* \mathrm{~b}}$ and Guillaume Vincent*a
}

a) Institut de Chimie Moléculaire et des Matériaux d'Orsay (ICMMO)

Université Paris-Saclay, CNRS

91405 Orsay, France

guillaume.vincent@universite-paris-saclay.fr

b) Laboratoire des Biomolécules (LBM), Département de Chimie Ecole Normale Supérieure, PSL University, Sorbonne Université, CNRS

75005 Paris, France

laurence.grimaud@ens.psl.eu; maxime.vitale@ens.psl.eu

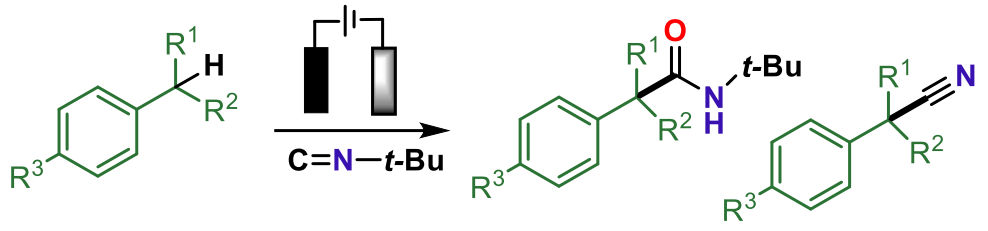

\begin{abstract}
We report the challenging direct carbamoylation or cyanation of benzylic $\mathrm{C}\left(\mathrm{sp}^{3}\right)-\mathrm{H}$ bonds with an isocyanide via an electrochemical process giving rise to structures which are encountered in several biologically relevant compounds and drugs. This transformation proceeds in mild conditions without the need of external oxidant and avoids the necessity to start from a prefunctionalized benzylic substrate or the deployment of the cation pool method. Anodic oxidation of the benzylic position and subsequent addition of the isocyanide leads to the formation of a $\mathrm{C}-\mathrm{C}$ bond and to a nitrilium cation which hydrolysis leads to alpha-aryl acetamide derivatives, while elimination of a $t$-butyl cation delivers alpha-aryl acetonitrile derivatives.
\end{abstract}

The functionalization of benzylic $\mathrm{C}\left(\mathrm{sp}^{3}\right)-\mathrm{H}$ bonds, via either metal-catalyzed $\mathrm{C}-\mathrm{H}$ activation or benzylic oxidation, represents a formidable way to convert feedstock raw materials such as alkyl benzenes into fine chemicals. ${ }^{1}$ In this field, photoredox catalysis and electrochemistry have emerged as proficient strategies, with which the use of stoichiometric quantities of strong oxidants and the generation of a substantial amounts of waste can be avoided. ${ }^{2}$ Notably, organic electrochemistry has been employed for the formation of valuable $\mathrm{C}-\mathrm{N},{ }^{3} \mathrm{C}-\mathrm{O}^{4}$ or C-halogen ${ }^{5}$ bonds at benzylic positions ( 1 to 2 , Scheme 1). ${ }^{2}$ Nonetheless, the formation of a $\mathrm{C}-\mathrm{C}$ bond by anodic oxidation stands challenging, and mainly relies on the use of activated substrates such as tetrahydroisoquinolines, xanthenes or parasubstituted phenols. ${ }^{6}$ Indeed, inactivated substrates entail them to be used in large excess, which severely impacts the synthetic potential of such benzylic functionalization processes. Although Yoshida's cation pool method can also be applied to benzylic substrates ( $\mathbf{1}$ to $\mathbf{4}$ via $\mathbf{A}$, Scheme 1$){ }^{7}$ it still remains limited to activated substrates such as diarylmethane precursors ${ }^{[7 \mathrm{~d}-\mathrm{g}]}$ or to the presence of an excess of a temporary stabilizing agent in the case of the stabilized cation pool approach ( $\mathbf{1}$ to $\mathbf{4}$ via $\mathbf{2}$, Scheme 1). ${ }^{[\mathrm{a}]}$ Hence, the development of new electrochemical methods which could permit the benzylic functionalization of alkyl arenes with C-based nucleophiles is highly desirable.

The direct introduction of a carbonyl group at a benzylic position is a valuable method to form alpha-aryl carbonyl moieties which are encountered in numerous biological active compounds such as the anti-inflammatory drugs ibuprofen, flurbiprofen, ketoprofen and naproxen or the glucokinase activator piragliatin. ${ }^{8}$

Related benzylic cyanation is relevant to alpha-aryl acetonitriles of biological interest such as emopamil, a calcium channel blocker or levocabastine, an antihistaminic (Figure 1). ${ }^{9}$ 
<smiles>CC(C)Cc1ccc(C(C)C(=O)O)cc1</smiles>

ibuprofen<smiles>CC(C(=O)O)c1ccc(-c2ccccc2)c(F)c1</smiles><smiles>CC(=O)C(C)c1cccc(C(=O)c2ccccc2)c1</smiles><smiles>COc1ccc2cc(C(C)C(=O)O)ccc2c1</smiles><smiles>CO[Sb](=O)(O)c1ccccc1</smiles>

ketoprofen<smiles>CN(CCCC(C#N)(CCCO)c1ccccc1)CCc1ccccc1</smiles><smiles>CCCCC(C)C(=O)I</smiles><smiles>c1cnccn1</smiles>

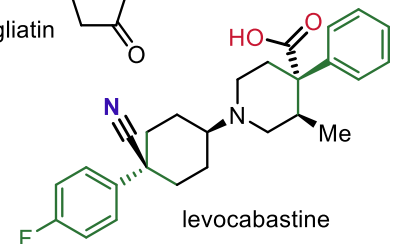

Figure 1. Benzylic carboxylic acids, amides and nitriles of pharmaceutical interest.

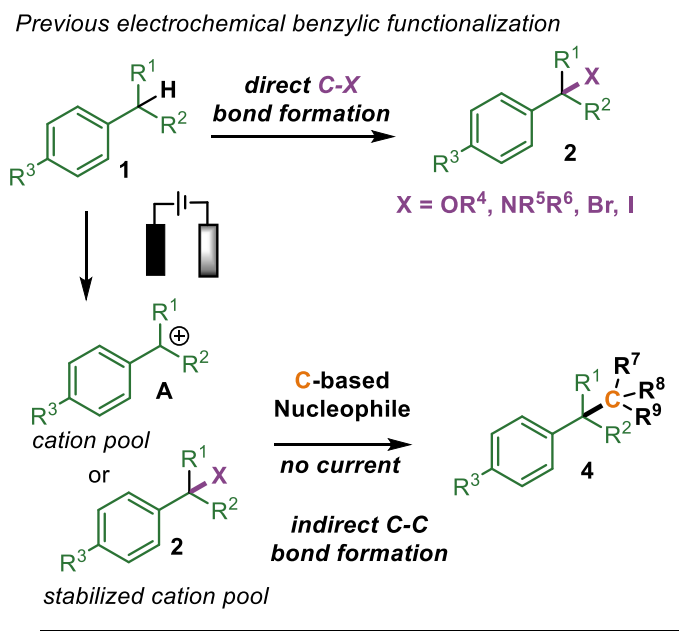

This work: direct C-C bond formation

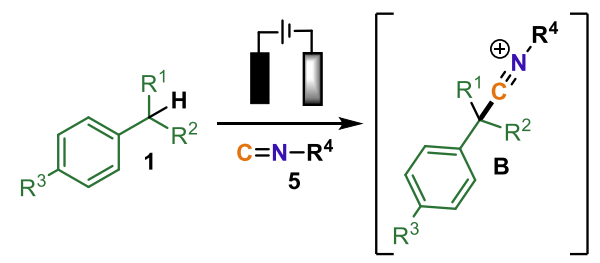

Scheme 1. Electrochemical benzylic functionalization.

In line with our interest in the electrochemical functionalization of aromatic compounds, ${ }^{10}$ we aimed to develop electrochemical benzylic carbonylation or cyanation through the addition of suitable nucleophilic carbonyl or cyanide surrogates onto the benzylic carbocation generated via anodic oxidation. ${ }^{11}$ To address this challenge, isocyanides 5 appeared to us to be reagents of choice since they should be capable to intercept an electron-deficient benzylic position of $\mathbf{1}$ leading to the generation of a transient nitrilium B (Scheme 1). Indeed, isocyanides are versatile compounds that are widely used in multicomponent reactions (IMCRs) such as the Ugi or Passerini reactions involving their additions to aldehydes or imines. ${ }^{12}$ To the best of our knowledge, the addition of isocyanides to benzylic position were only reported for particularly activated bisbenzylic substrates or alpha-arylamines with benzoyl peroxide and a copper catalyst. ${ }^{13}$ However, the deployment of isocyanides in electrochemical set-up are scarce. In this context, we recently demonstrated that isocyanides are compatible with electrochemical 
conditions for oxidative Ugi-type processes through the oxidation of an amine or alcohol with an electrocatalyst. ${ }^{14}$ More recently, isocyanides were also employed for the electrochemical synthesis of carbodiimides, carbonimidothioates or S-thiocarbamates. ${ }^{15}$

To test, the feasibility of this approach, we selected ethyl biphenyl 1a as substrate. Inspired by the electrochemical amination of Xu, we performed the reaction in presence of HFIP which is key to perform the benzylic oxidation. ${ }^{3 e}$ With cyclohexyl isocyanide 5a, we were able to observe the formation in low yield of hexafluoro-iso-propyl imidate 6aa which resulted from the desired addition of the isocyanide to the benzylic position accompanied with the reaction with HFIP. The competitive formation of ether 7a via addition of HFIP to the oxidized benzylic position was observed. To strongly diminish this undesired reaction, the use of the more nucleophilic $t$-butyl isocyanide $\mathbf{5} \mathbf{b}^{16}$ was necessary to obtain a complete consumption of 1a. The crude ${ }^{1} \mathrm{H}$ NMR showed that $N$-t -butyl imidate $\mathbf{6 a b}$ was the main product accompanied by nitrile $\mathbf{9 a}$ which also results from the addition of $\mathbf{5 b}$ to $\mathbf{1 a} \cdot{ }^{17}$ However $\mathbf{6 a b}$ is partly hydrolyzed into desired amide 8ab upon purification on silica gel. Therefore, we decided to do an acidic treatment at the end of the electrolysis to completely convert imidate $\mathbf{6 a b}$ into amide $\mathbf{8 a b}$.

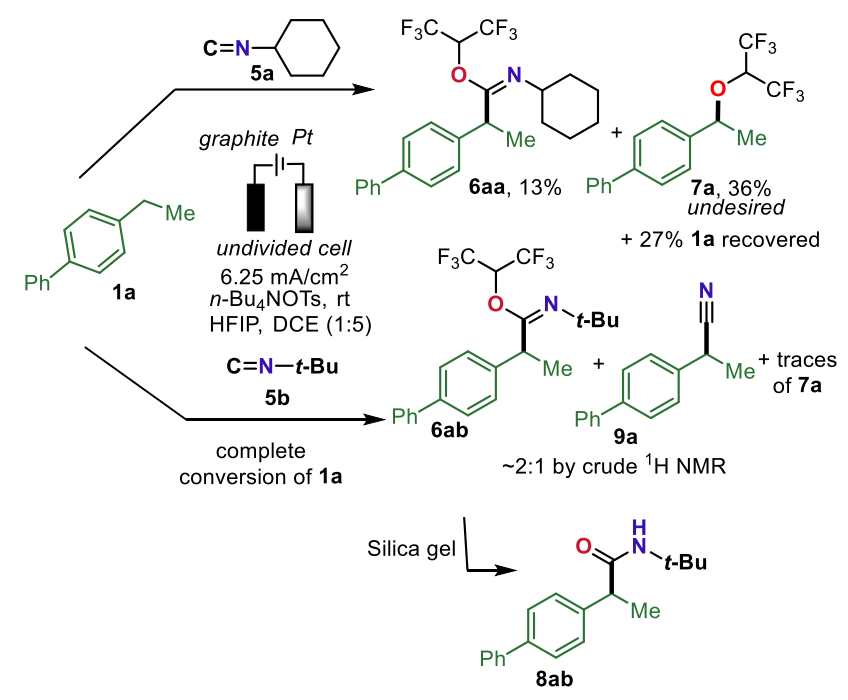

Scheme 2. Electrochemical benzylic carbamoylation/cyanation with isocyanides.

Upon evaluation of the parameters of the reaction, electrolysis in an undivided cell at a constant current of $6.25 \mathrm{~mA} / \mathrm{cm}^{2}$ with a graphite anode and a platinum-plated cathode in a 5:1 mixture of dichloroethane and HFIP with tetrabutyl ammonium tosylate as electrolyte at room temperature followed by hydrolysis with acetic acid and water at room temperature to generate 8ab from 6ab appeared to be the optimal conditions (Table 1).$^{18}$ Overall, benzylic amide $8 \mathbf{a b}$ was produced with $47 \%$ along with $17 \%$ of nitrile 9a which represent a 64\% yield of addition of the isocyanide onto the benzylic position. The nature of the anion of the tetrabutyl ammonium electrolyte proved to be important. The tosylate salt (entry 1) ensured a better conversion of 1a than the nitrate salt (entry 2) and a better selectivity of the addition of the isocyanide over HFIP to 1a than the tetrafluoroborate or hexafluorophosphate salts (entries 3-4). The use of both HFIP and dichloroethane is key to promote the C-C bond formation with an optimal ratio of 1:5 (entries 1,5,6) since performing the reaction in pure dichloroethane or pure HFIP lead to the formation of complex mixtures (entries 7-8). Replacing dichloroethane by acetonitrile led a lower conversion of 7a as well as the formation of biphenyl-methyl- ketone $\mathbf{1 0}$ as the main product (entry 9). Replacement of HFIP by a more nucleophilic alcohol such as methanol indeed led to benzylic ether 7c and acetal 11 (entry 10); even hindered $t$-butanol is more prone to add to the benzylic position than the isocyanide (entry 11). Decreasing or increasing the current density was also detrimental to the yield (entries 12-13). A lower charge of $3 \mathrm{~F} / \mathrm{mol}$ instead of $5.6 \mathrm{~F} / \mathrm{mol}$ resulted in a sharply reduced oxidation of starting 1a (entry 14). Replacing the platinum cathode by a graphite cathode led to a slight decreased of the yield (entry 15) while changing the graphite anode by a platinum anode was sharply detrimental to the conversion of 1a (entry 16). 
Table 1. Optimisation of the electrochemical reaction between ethyl biphenyl and $t$-Bu isocyanide followed by acidic hydrolysis.

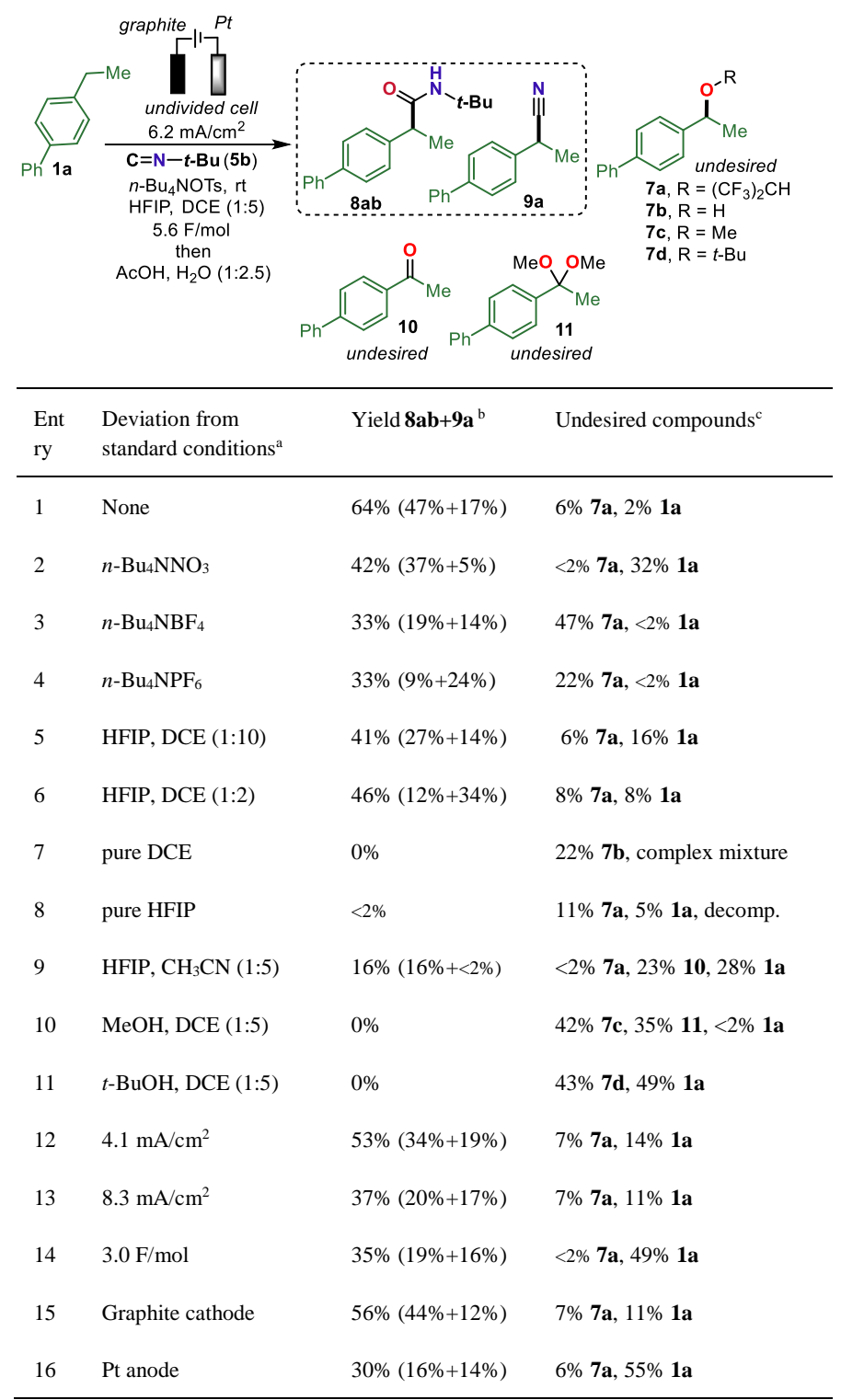

a Undivided cell, graphite-SK50 anode ( $1.5 \mathrm{~cm}$ x $0.8 \mathrm{~cm}$ x $0.2 \mathrm{~cm}$ submerged), platinum-plated cathode $(1.5 \mathrm{~cm} \times 0.8 \mathrm{~cm} \times 0.2 \mathrm{~cm}$ submerged), $7.5 \mathrm{~mA}, 1 \mathrm{a}(0.2$ $\mathrm{mmol}), \mathbf{5 b}(0.5 \mathrm{mmol}), n$-Bu4NOTs $(0.2 \mathrm{mmol}), 3 \mathrm{~mL}$ of DCE/HFIP (5:1), room temperature; argon; b sum of isolated yield of 8ab+9a (isolated yields of each 8ab and $9 \mathbf{a}$ in parenthesis); c isolated yield.

We then studied the scope of this electrochemical carbamoylation/cyanation of benzylic secondary carbons with $t$-butyl isocyanide (Scheme 3).$^{19}$ para-Bromo and para-cyano derivatives of ethyl biphenyl $(\mathbf{8 b b} / 9 \mathbf{b}$ and $\mathbf{8 c b})$ were also competent acceptors of the carbon nucleophile. We were able to resolve the structure of amide $\mathbf{8 b b}$ by X-ray analysis of a monocrystal of this compound. ${ }^{20}$ Other substituents at the para position of ethyl benzene such as a methoxy, ethyl, iso-butyl, fluoro, chloro or bromo substituents delivered satisfactorily the $\mathrm{C}-\mathrm{C}$ bond formation products $(\mathbf{8 d b}-\mathbf{i b} / \mathbf{9 d}-\mathbf{f})$.

The length of the alkyl chain which contains the benzylic $\mathrm{CH}_{2}$ to be functionalized was also evaluated with success in the cases of a propyl $(\mathbf{8 j \mathbf { j }} / \mathbf{9 j} \mathbf{j})$ instead of an ethyl as well for tetrahydronaphtalene derivatives $(\mathbf{8 k b}, \mathbf{l b} / \mathbf{9 k}, \mathbf{l})$. In all these cases, the amide is predominant in comparison to the nitrile.

In contrast, with more activated benzylic substrates such as biphenylmethane derivatives, the nitrile $(\mathbf{9 m}, \mathbf{n})$ is the major product over the amide $(\mathbf{8 m b}, \mathbf{n b})$. Very interestingly, xanthene resulted in the formation of alpha-imino-nitrile $\mathbf{1 2}$ which resulted in the interception of nitrilium $\mathbf{B}$ by a second isocyanide. 

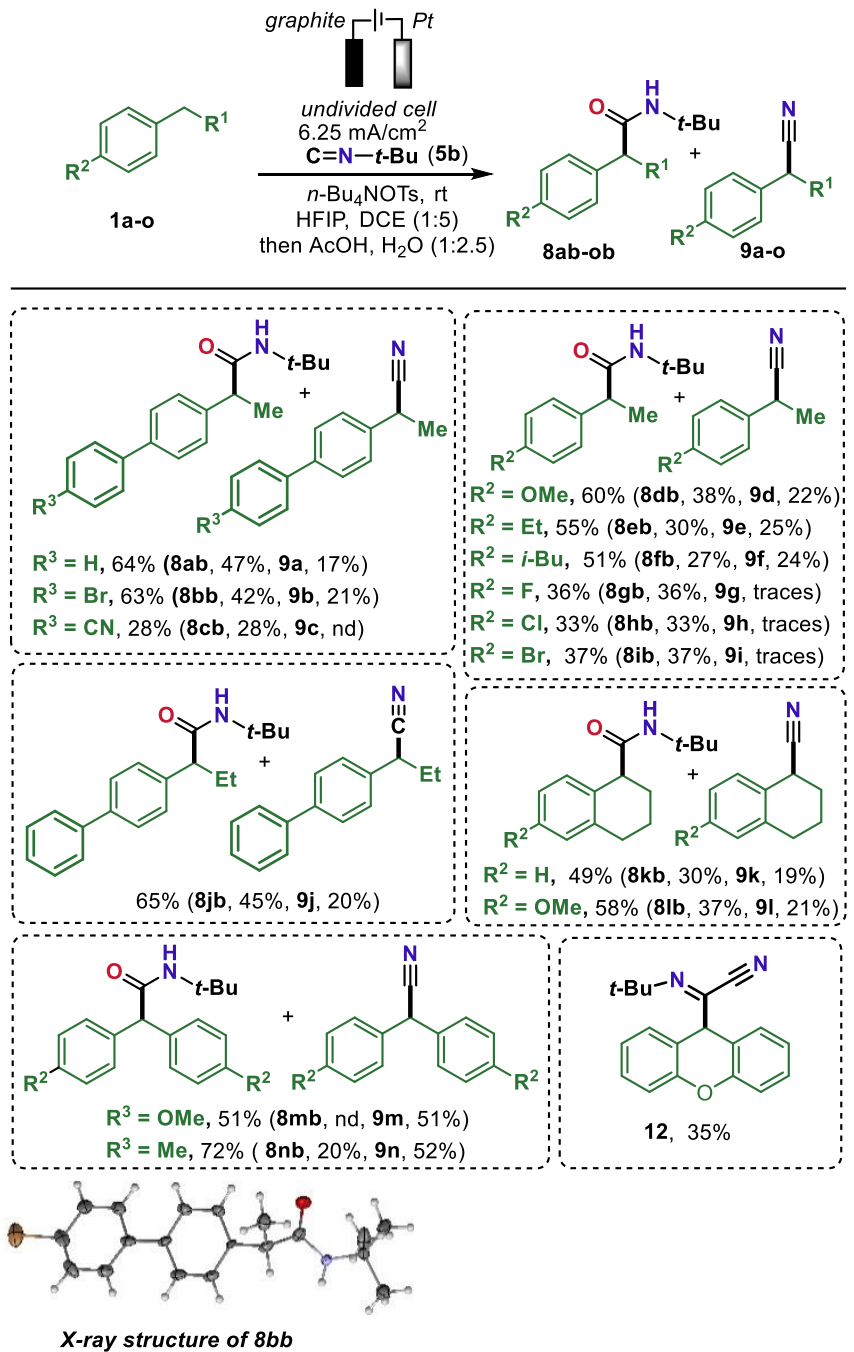

Scheme 3. Electrochemical carbonylation/cyanation of benzylic secondary carbons.

$t$-Butyl isocyanide $\mathbf{5 b}$ could also add to a benzylic tertiary carbon in these electrochemical conditions leading to quaternary-center -containing nitriles 9p-v (Scheme 4). Indeed, highly activated triphenyl methane delivered efficiently triphenyl acetonitrile $9 \mathbf{p}$. The iso-propyl group is also suitable for benzylic C-H cyanation of substrates para-substituted with methoxy, methyl, iso-propyl, bromide or phenyl groups $(\mathbf{9 q - u})$. Surprisingly, ipso-substitution of the iso-propyl group by the isocyanide leading to benzamides 13q-u was also observed. The sec-butyl group could also lead to trisubstituted acetonitrile 9v. 


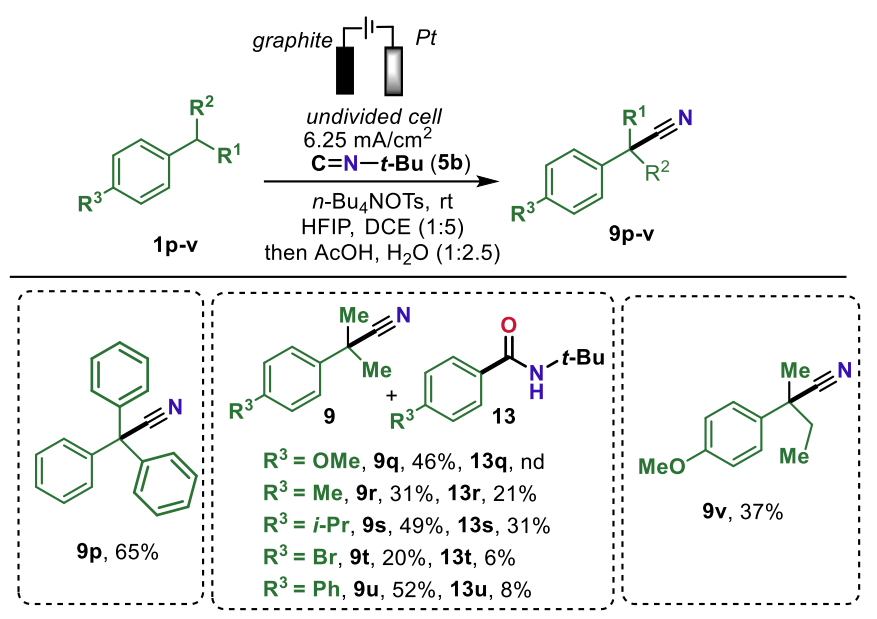

Scheme 4. Electrochemical cyanation of benzylic tertiary carbons.

In terms of post-synthetic transformations (Scheme 5), the $t$-butyl group of amide 8ab is easily removed with TFA to deliver primary amide $\mathbf{1 4}$ (Scheme 5). The $t$-Bu amide 8ab could also be hydrolyzed at room temperature to generate the corresponding carboxylic acid 15. Alternatively, after the electrolysis of 1a and evaporation of the solvents, the crude mixture of amide 8ab and nitrile 9a is directly hydrolyzed into carboxylic acid $\mathbf{1 5}$ with aqueous chlorhydric acid.
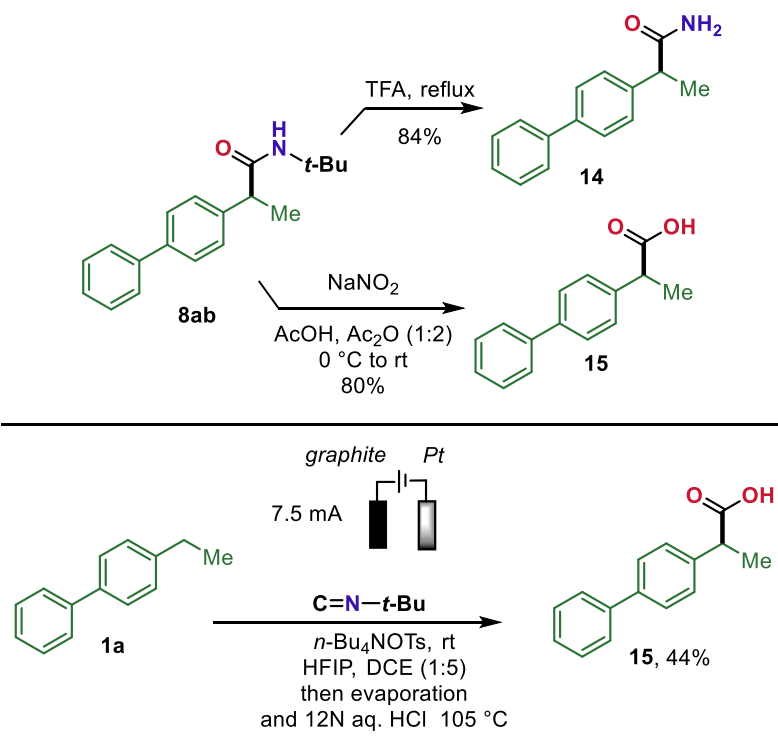

Scheme 5. Synthesis of the corresponding primary amide or carboxylic acid.

From a mechanistic point of view, the anodic oxidation of the aromatic moiety of $\mathbf{1}$ would provide the corresponding radical cation $\mathbf{C}$ which could evolve through various scenarios depending on the substitution pattern of the arene. With a substituent at the para-position, ${ }^{19}$ the first radical cation could lose a proton to generate the benzyl radical, in turn oxidized to the corresponding benzylic carbocation A. The latter would then be trapped by $t$-BuNC, ${ }^{21}$ and the corresponding nitrilium $\mathbf{B}$ would either fragment to form the cyano derivative $\mathbf{9}$ (via the loss of the tert-butyl cation, further evolving to isobutene after proton release), ${ }^{17}$ or generate imidate $\mathbf{F}$ upon capture by HFIP. Amide $\mathbf{8}$ would finally be generated by hydrolysis. In presence of an iso-propyl group, ipso-substitution via $\mathbf{D}$ becomes also possible thus liberating a relatively stable iso-propyl secondary carbocation and delivering the 
corresponding imidate after reaction of aromatic nitrilium $\mathbf{E}$ with HFIP and the benzamide $\mathbf{1 3}$ after hydrolysis.

This complex mechanistic picture is completed by proton reduction at the cathode, liberating hydrogen gas. As shown during the optimization of the process, low yields were obtained in plain dichloroethane and the addition of HFIP, even if nucleophilic enough to trap the nitrilium $\mathbf{B}$ before fragmentation, proved essential to finely tune and reach the desired reactivity. While other polar protic co-solvents such as $\mathrm{MeOH}$ or $t \mathrm{BuOH}$ induced the preferential formation of the corresponding benzyl ethers, HFIP allows to lower the oxidation potential of ethyl biphenyl 1a (Figure 2a) and most certainly subtly favors the selective oxidation of the starting material vs oxidation of the product(s) (Figure 2b), as previously proposed by $\mathrm{Xu} .{ }^{3 \mathrm{e}}$ Indeed, the cyclic voltammetry proved that the oxidation potential of ethyl biphenyl $\left(E_{1 / 2}=+1.61 \mathrm{~V}\right.$ vs $\left.\mathrm{Ag} \mid \mathrm{AgCl}\right)$ is slightly lower than those of the nitrile $\left(E_{1 / 2}=+1.71 \mathrm{~V}\right)$, of the imidate $\left(E_{1 / 2}=+1.62 \mathrm{~V}\right)$ and of the amide $\left(\left(E_{1 / 2}=+1.75 \mathrm{~V}\right)-\right.$ the latter could be in situ formed in small amounts due to traces of water) in a mixture of HFIP and DCE (1:5).

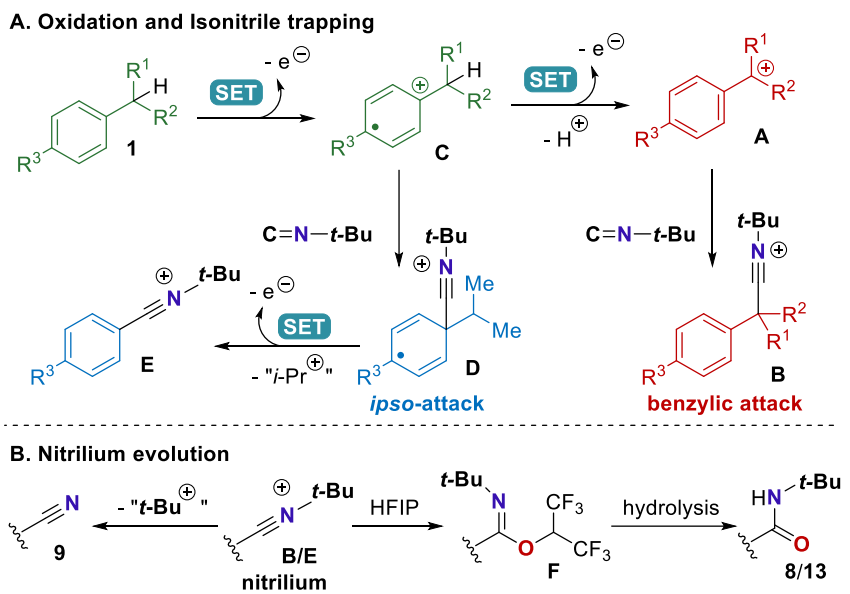

Scheme 5. Mechanistic proposal. 

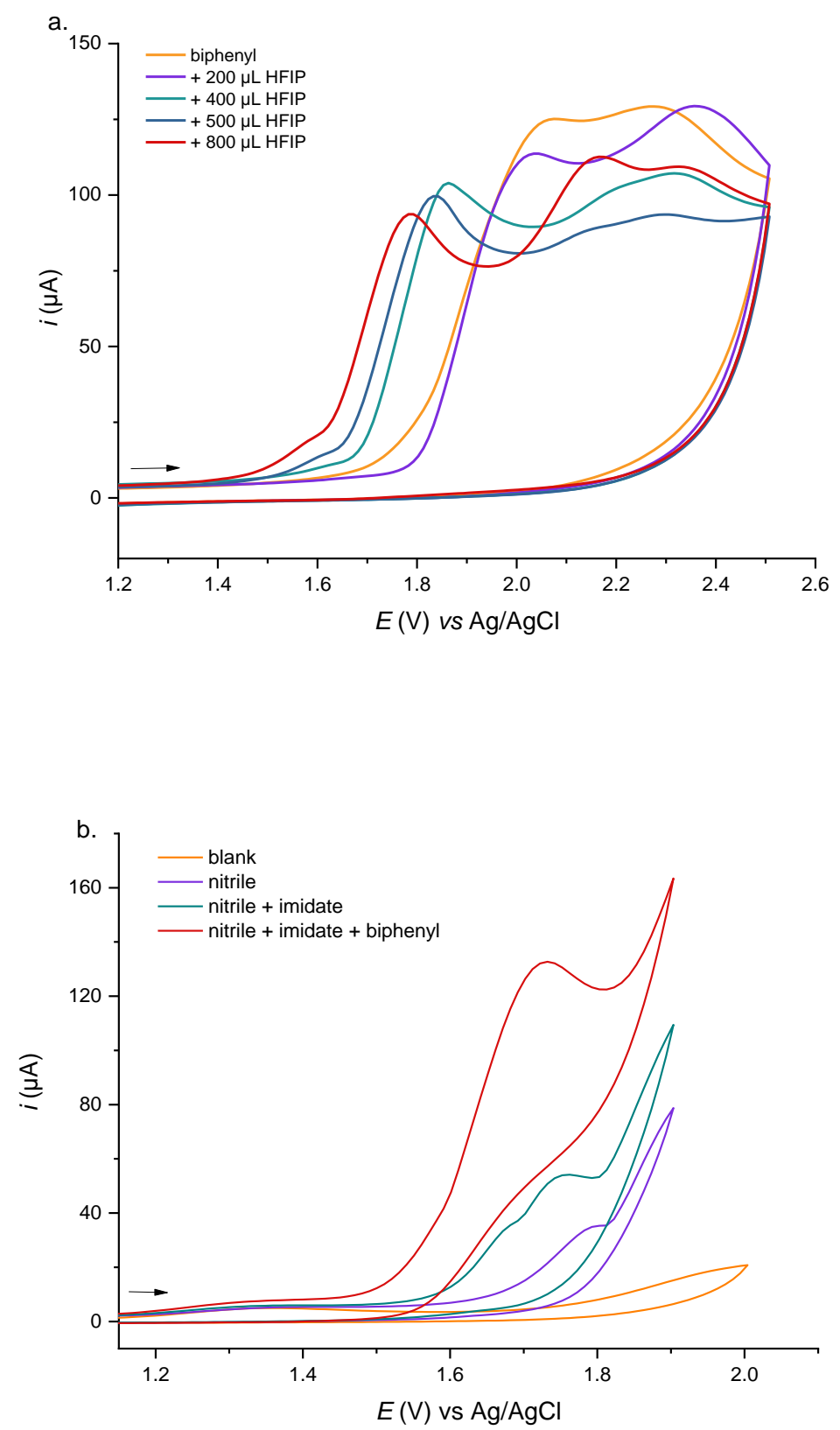

Figure 2. Cyclic voltammetry studies. (CV were performed in a $0.1 \mathrm{M}$ solution of $n-\mathrm{Bu}_{4} \mathrm{~N} . \mathrm{BF}_{4}$ in the solvent using a glassy carbon disk $(d=3 \mathrm{~mm})$ as working electrode, a platinum wire as counter electrode and a $\mathrm{Ag} / \mathrm{AgCl}$ as reference at a scan rate of $0.05 \mathrm{Vs}^{-1}$ at $20{ }^{\circ} \mathrm{C}$ ). a). $2 \mathrm{mM}$ of ethyl biphenyl and $10 \mathrm{mM}$ of $n$-BunOTs in DCE (5 $\mathrm{mL}$ ) with incremental addition of respectively 200, 200, 100 and $300 \mathrm{~mL}$ of HFIP (total volume of HFIP is indicated on the CV). b). $2 \mathrm{mM}$ of each compounds with $2 \mathrm{mM}$ of $n$-Bu $\mathrm{HOT}_{\mathrm{NO}}$ in a 5:1 DCE:HFIP mixture of solvents $(5 \mathrm{~mL})$.

In conclusion, we were able to develop a direct electrochemical benzylic carbamoylation or cyanation process via the anodic oxidation of arenes at the benzylic position followed by the addition of isocyanides. It allows to access valuable alpha-aryl acetamide or acetonitrile derivatives without the use of prefunctionalized starting materials. This electrochemical C-C bond formation via an oxidative $\mathrm{C}\left(\mathrm{sp}^{3}\right)-\mathrm{H}$ functionalization proceeds in an undivided cell under mild conditions at room temperature 
without stoichiometric oxidant or transition-metal catalyst and does not need to rely on the cation-pool approach.

\section{Acknowledgements}

ST thanks the China Scholarship Council (CSC) for her PhD fellowship. We also gratefully acknowledge the ANR (ANR-20-CE07-0020; "ELMER"), the Université Paris-Saclay and the CNRS for financial support.

1 a) H. M. L. Davies, J. R. Manning, Nature 2008, 451, 417-424; b) R. Yazaki, T. Ohshima, Tetrahedron Lett. 2019, 60, 151225 .

2 M. Oliva, G. A. Coppola, E. V. V. der Eycken, U. K. Sharma, Adv. Synth. Catal. 2021, 363, 1810-1834.

3 For selected intermolecular examples: a) T. Morofuji, A. Shimizu, J. Yoshida, J. Am. Chem. Soc. 2014, 136, 4496-4499; b) R. Hayashi, A. Shimizu, Y. Song, Y. Ashikari, T. Nokami, J. Yoshida, Chem. - Eur. J. 2017, 23, 61-64; c) M. A. Kabeshov, B. Musio, S. V. Ley, React. Chem. Eng. 2017, 2, 822-825; d) L. Niu, C. Jiang, Y. Liang, D. Liu, F. Bu, R. Shi, H. Chen, A. D. Chowdhury, A. Lei, J. Am. Chem. Soc. 2020, 142, 17693-17702; e) Z.-W. Hou, D.-J. Liu, P. Xiong, X.-L. Lai, J. Song, H.-C. Xu, Angew. Chem. Int. Ed. 2021, 60, 2943-2947; f) Z. Ruan, Z. Huang, Z. Xu, S. Zeng, P. Feng, P.-H. Sun, Sci. China Chem. 2021, 64, 800807; g) T. Shen, T. H. Lambert, J. Am. Chem. Soc. 2021, 143, 8597-8602; h) Z.-W. Hou, L. Li, L. Wang, Org. Chem. Front. 2021, 8, 4700-4705; i) Y. K. Nagare, I. A. Shah, J. Yadav, A. P. Pawar, R. Choudhary, P. Chauhan, I. Kumar, J. Org. Chem. 2021, 86, 9682-9691; For intramolecular examples: j) S. Herold, D. Bafaluy, K. Muñiz, Green Chem. 2018, 20, 3191-3196; k) F. Wang, S. S. Stahl, Angew. Chem. Int. Ed. 2019, 58, 6385-6390; 1) P. Nikolaienko, M. Jentsch, A. P. Kale, Y. Cai, M. Rueping, Chem. - Eur. J. 2019, 25, 7177-7184; m) A. Liu, T. Guo, S. Zhang, H. Yang, Q. Zhang, Y. Chai, S. Zhang, Org. Lett. 2021, DOI 10.1021/acs.orglett.1c02128.

4 Selected examples: a) Y. Ashikari, T. Nokami, J. Yoshida, Org. Lett. 2012, 14, 938-941; b) H. Wang, K. Liang, W. Xiong, S. Samanta, W. Li, A. Lei, Sci. Adv. 2020, 6, eaaz0590; c) P. Xiong, H.-B. Zhao, X.-T. Fan, L.-H. Jie, H. Long, P. Xu, Z.-J. Liu, Z.-J. Wu, J. Cheng, H.-C. Xu, Nat. Commun. 2020, 11, 2706.

5 a) T. Raju, K. Kulangiappar, M. A. Kulandainathan, A. Muthukumaran, Tetrahedron Lett. 2005, 46, $7047-$ 7050; b) M. Rafiee, F. Wang, D. P. Hruszkewycz, S. S. Stahl, J. Am. Chem. Soc. 2018, 140, $22-25$.

6 a) X.-H. Ho, S. Mho, H. Kang, H.-Y. Jang, Eur. J. Org. Chem. 2010, 4436-4441; b) N. Fu, L. Li, Q. Yang, S. Luo, Org. Lett. 2017, 19, 2122-2125; c) Y.-Z. Yang, Y.-C. Wu, R.-J. Song, J.-H. Li, Chem. Commun. 2020, 56, 7585-7588; d) Q. Zhang, X. Chang, L. Peng, C. Guo, Angew. Chem. Int. Ed. 2019, 58, 6999-7003; e) P. Xu, P.-Y. Chen, H.-C. Xu, Angew. Chem. Int. Ed. 2020, 59, 14275-14280.

7 Stabilized cation pool: a) R. Hayashi, A. Shimizu, J. Yoshida, J. Am. Chem. Soc. 2016, 138, 8400-8403; b) Y. Imada, J. L. Röckl, A. Wiebe, T. Gieshoff, D. Schollmeyer, K. Chiba, R. Franke, S. R. Waldvogel, Angew. Chem. Int. Ed. 2018, 57, 12136-12140; c) J. L. Röckl, Y. Imada, K. Chiba, R. Franke, S. R. Waldvogel, ChemElectroChem 2019, 6, 4184-4187; Cation pool from biarylmethane: d) M. Okajima, K. Soga, T. Nokami, S. Suga, J. Yoshida, Org. Lett. 2006, 8, 5005-5007; e) T. Nokami, K. Ohata, M. Inoue, H. Tsuyama, A. Shibuya, K. Soga, M. Okajima, S. Suga, J. Yoshida, J. Am. Chem. Soc. 2008, 130, 10864-10865; f) M. Okajima, K. Soga, T. Watanabe, K. Terao, T. Nokami, S. Suga, J. Yoshida, Bull. Chem. Soc. Jpn. 2009, 82, 594-599; g) T. Nokami, T. Watanabe, N. Musya, T. Suehiro, T. Morofuji, J. Yoshida, Tetrahedron 2011, 67, 4664-4671.

8 For non-electrochemical direct C-H benzylic carbamoylation: a) P. Xie, C. Xia, H. Huang, Org. Lett. 2013, 15, 3370-3373; b) Z. Han, D. Chaowei, L. Lice, M. Hongfei, B. Hongzhong, L. Yufeng, Tetrahedron 2018, 74, 3712-3718; for direct C-H benzylic carboxylation: c) A. L. Shabanov, N. M. Seidov, U. A. Gasanova, Z. O. Kakhramanova, M. M. Gasanova, Russ. J. Org. Chem. 2009, 45, 26-29; d) P. Xie, Y. Xie, B. Qian, H. Zhou, C. Xia, H. Huang, J. Am. Chem. Soc. 2012, 134, 9902-9905; e) Q.-Y. Meng, T. E. Schirmer, A. L. Berger, K. Donabauer, B. König, J. Am. Chem. Soc. 2019, 141, 11393-11397; f) N. Ishida, Y. Masuda, Y. Imamura, K. Yamazaki, M. Murakami, J. Am. Chem. Soc. 2019, 141, 19611-19615; via a remote activation strategy: g) L. Song, D.-M. Fu, L. Chen, Y.-X. Jiang, J.-H. Ye, L. Zhu, Y. Lan, Q. Fu, D.-G. Yu, Angew. Chem. Int. Ed. 2020, 59, 21121-21128.

9 For non-electrochemical direct $\mathrm{C}-\mathrm{H}$ benzylic cyanation with cyanide-containing reagents: a) M. Lemaire, J. Doussot, A. Guy, Chem. Lett. 1988, 17, 1581-1584; b) S. Kamijo, T. Hoshikawa, M. Inoue, Org. Lett. 2011, 13, 5928-5931; c) W. Zhang, F. Wang, S. D. McCann, D. Wang, P. Chen, S. S. Stahl, G. Liu, Science 2016, 353, 1014-1018; d) M.-X. Sun, Y.-F. Wang, B.-H. Xu, X.-Q. Ma, S.-J. Zhang, Org. Biomol. Chem. 2018, 16, 1971-1975; e) K. Kim, S. Lee, S. H. Hong, Org. Lett. 2021, 23, 5501-5505; via a remote activation strategy: f) Z. Zhang, X. Zhang, D. A. Nagib, Chem 2019, 5, 3127-3134; g) C.-Y. Wang, Z.-Y. Qin, Y.-L. Huang, R.-X. Jin, Q. Lan, X.-S. Wang, iScience 2019, 21, 490-498; h) X. Bao, Q. Wang, J. Zhu, Angew. Chem. Int. Ed. 2019, 58, 2139-2143.

10 a) J. Wu, Y. Dou, R. Guillot, C. Kouklovsky, G. Vincent, J. Am. Chem. Soc. 2019, 141, 2832-2837; b) J. Wu, H. Abou-Hamdan, R. Guillot, C. Kouklovsky, G. Vincent, Chem. Commun. 2020, 56, 1713-1716; c) J. Wu, R. Guillot, C. Kouklovsky, G. Vincent, Adv. Synth. Catal. 2020, 362, 1712-1719.

11 For review on electrochemical carboxylation of benzylic halides with reduction of the halide at the cathode with a sacrificial electrode: a) R. Matthessen, J. Fransaer, K. Binnemans, D. E. D. Vos, Beilstein J. Org. Chem. 2014, 10, 2484-2500; For a carboxylation of benzylic alcohol via paired electrolysis: b) L. Song, N. 
Fu, B. G. Ernst, W. H. Lee, M. O. Frederick, R. A. DiStasio, S. Lin, Nat. Chem. 2020, 12, 747-754; For an electrochemical hydrocyanation of styrenes leading to alpha-aryl acetonitriles: c) L. Song, N. Fu, B. G. Ernst, W. H. Lee, M. O. Frederick, R. A. DiStasio, S. Lin, Nat. Chem. 2020, 12, 747-754.

12 a) V. Nenajdenko, Isocyanide Chemistry: Applications in Synthesis and Material Science, John Wiley \& Sons, 2012; b) A. Dömling, Chem. Rev. 2006, 106, 17-89; c) L. Banfi, R. Riva, in Org. React., American Cancer Society, 2005, pp. 1-140; d) L. El Kaim, L. Grimaud, Tetrahedron 2009, 65, 2153-2171; e) M. T. Nazeri, H. Farhid, R. Mohammadian, A. Shaabani, ACS Comb. Sci. 2020, 22, 361-400; f) K. Yang, F. Zhang, T. Fang, C. Li, W. Li, Q. Song, Nat. Commun. 2021, 12, 441.

13 a) T. Brandhofer, A. Gini, S. Stockerl, D. G. Piekarski, O. García Mancheño, J. Org. Chem. 2019, 84, 1299213002; b) A. Gini, M. Uygur, T. Rigotti, J. Alemán, O. García Mancheño, Chem. - Eur. J. 2018, 24, 1250912514.

14 a) N. Pan, J. Ling, R. Zapata, J.-P. Pulicani, L. Grimaud, M. R. Vitale, Green Chem. 2019, 21, 6194-6199; b) N. Pan, M. Xinen Lee, L. Bunel, L. Grimaud, M. R. Vitale, ACS Org. Inorg. Au 2021, 1, 18-22.

15 a) B. K. Malviya, P. K. Jaiswal, V. P. Verma, S. S. Badsara, S. Sharma, Org. Lett. 2020, 22, 2323-2327; b) Z. Guan, S. Zhu, S. Wang, H. Wang, S. Wang, X. Zhong, F. Bu, H. Cong, A. Lei, Angew. Chem. Int. Ed. 2021, 60, 1573-1577; c) B. K. Malviya, V. P. Verma, S. Sharma, Org. Biomol. Chem. 2021, doi:10.1039/D1OB01701B.

16 V. V. Tumanov, A. A. Tishkov, H. Mayr, Angew. Chem. Int. Ed. 2007, 46, 3563-3566.

17 For precedents of nitrile formation from isocyanides by fragmentation; via an ionic mechanism: a) Y. Ito, H. Kato, H. Imai, T. Saegusa, J. Am. Chem. Soc. 1982, 104, 6449-6450; b) Y. Ito, H. Imai, K. Segoe, T. Saegusa, Chem. Lett. 1984, 13, 937-940; via a radical mechanism: c) G. Stork, P. M. Sher, J. Am. Chem. Soc. 1983, 105, 6765-6766; d) R. Leardini, D. Nanni, G. Zanardi, J. Org. Chem. 2000, 65, 2763-2772; e) J. Lei, J. Huang, Q. Zhu, Org. Biomol.

18 Cyclohexyl imidate $\mathbf{6 a}$ is more stable than $t$-butyl imidate $\mathbf{6 b}$. Hydrolysis of $\mathbf{6 a}$ (after the electrolysis of 1a with 5a) into the corresponding $\mathrm{N}$-cyclohexyl amide 8aa needs to be performed at $70{ }^{\circ} \mathrm{C}$ for $16 \mathrm{~h}$ (see supporting information).

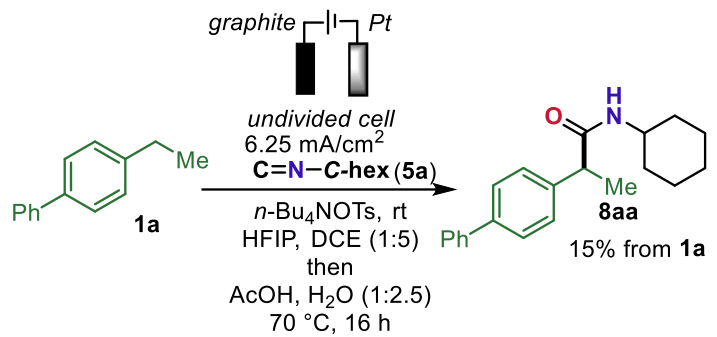

19 If the para position of the benzylic position is not blocked, the isocyanide adds mainly onto the aromatic ring as illustrated on the following examples. The direct addition of the isocyanide on the radical cation $\mathbf{C}$ lead to an aromatic nitrilium such as $\mathbf{E}$ after loss of an aromatic proton, which could further evolve to benzamide 13v or aromatic nitrile $9 \mathbf{w}$.

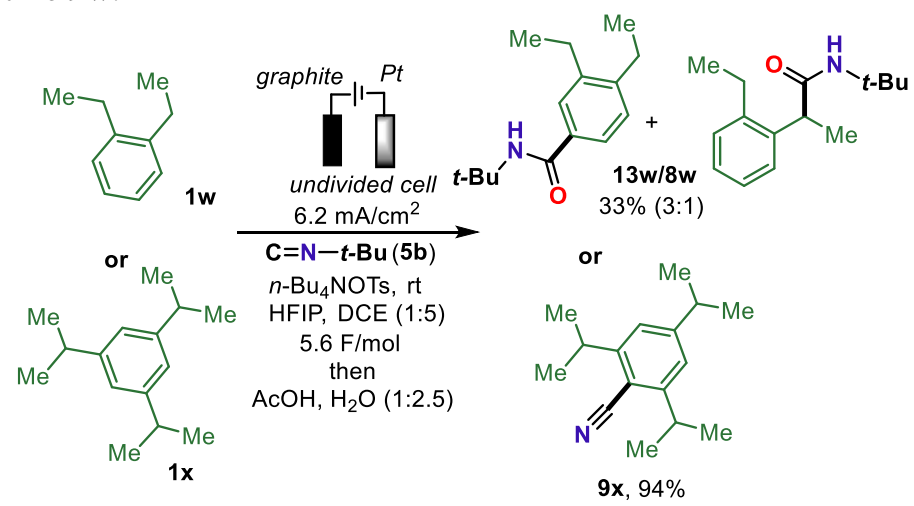

20 Interestingly, this crystal displays an unusual high number of 8 molecules not linked by symmetry $\left(Z^{\prime}=8\right)$. CCDC 2112159 contains the supplementary crystallographic data for this paper. These data can be obtained free of charge from The Cambridge Crystallographic Data Centre via www.ccdc.cam.ac.uk/data_request/cif.

21 As mentioned in the optimization part, in the case of a less nucleophilic isocyanide (i.e. cyclohexylisocyanide), the benzylic carbocation can competitively be trapped by HFIP to yield 7a (Cf Scheme 2). Worthy of note, we ruled out that hexafluoro-iso-propanol ether 7a could be a transient intermediate because no amide 8a nor nitrile 9a was observed when 7a was reengaged in the reaction conditions with isonitrile $\mathbf{5 b}$. 